\title{
Understanding perceived environment quality in affecting tourists' environmentally responsible behaviours: A broken windows theory perspective
}

\begin{abstract}
Encouraging individuals' environmentally responsible behaviours (ERBs) is becoming increasingly important for tourism destination management. This study was designed to investigate the formation of the ERBs of tourists from a broken windows theory perspective. Results from a sample of 307 tourists highlighted the antecedent role of tourists' perceived environment quality among the relationships between the variables of theory of planned behaviour (TPB), moral obligation, and the intention to engage in ERBs. The results of multiple mediation analysis revealed that the TPB variables and moral obligation act as full mediators in the effect of perceived environment quality on ERBs intention. The relative importance of the TPB variables and moral obligation in predicting the intention to engage in ERBs were also compared in this study.
\end{abstract}

Keywords: environmentally responsible behaviour; theory of planned behaviour; broken windows theory; perceived environment quality; destination management; multiple mediation analysis

\section{Introduction}

With the unprecedented development of tourism, increasing concerns have been raised regarding the negative impacts of tourists on nature and the environment (Miller \& Twining-Ward, 2005; Ballantyne \& Packer, 2011). The promotion of environmentally responsible behaviours (ERBs) among tourists has become an important issue for both the government and industry practitioners (Kim, Airey, \& Szivas, 2011; Wu, Huang, Liu \& Law, 2013); it is critical to determine the drivers and behaviours of tourists concerning environmental conservation.

A substantial stream of research on ERBs is based on the theory of planned behaviour (TPB) or the extended TPB, in which attitude, subjective norm, perceived behavioural control, and moral obligation were indicated as important predictors of individual's intention to engage in ERBs (Chen \& Tung, 2014; Han, 2015; Goh, Ritchie $\&$ Wang, 2017). Compared with the research efforts on the role of TPB components (e.g. attitude, subjective norm and perceived behavioural control) in affecting ERBs, little research has empirically investigate the antecedents of TPB components leading to ERBs. Much of the existing tourism research focused on the change in belief as a precondition of TPB variables that lead to ERBs (Ballantyne, Packer, \& Sutherland, 2011; Chen \& Tung, 2014), where tourism experience and environmental concern of visitors were determined as primary beliefs that influence affective components (e.g. TPB variables). 
However, as Ajzen (2015) noted in his updated study on the TPB model, large changes in beliefs can only bring limited changes in TPB components. The development of the TPB calls for more considerations of physical resources and contextual factors in promoting an effective behavioural change. One theoretical perspective concerning how physical resources (i.e. surrounding environment) shape the behaviours of individuals is the broken windows theory (Wilson \& Kelling, 1982). The broken windows theory indicates that first impressions of a place (e.g. neighbourhood) are often more important than early intervention (Sampson \& Raudenbush, 2004). In the case of tourism, the perceived quality of a destination's physical appearance (thereafter called perceived environment quality), as tourists' first impression of the destination, might play a significant role in their environment-related attitudes and behaviours. From the perspective of the broken windows theory (Lang et al., 2010), the dirty and messy environment of a tourism destination can lead to more non-ecological phenomena, such as littering and trampled grasslands, and can potentially inhibit pro-environmental actions. Although some studies have looked at the effect of perceived environment quality on tourism experience (Lee, 2016; Zhang, Zhang, \& Law, 2014), there is a major lack of empirical research determining the role of perceived environment quality as the antecedent of the TPB components to explain the formation of pro-environmental behaviours.

While the TPB model has proven to be helpful in comprehending tourists' proenvironmental intentions and behaviours (Brown, Ham, \& Hughes, 2010; Powell \& Ham, 2008; Wu et al., 2013), it is suggested that moral considerations should be added into the research framework (Abrahamse, Steg, Gifford, \& Vlek, 2009; Chen \& Tung, 2014). Emerging tourism studies on ERBs comprised both the original TPB variables and morality variables (Chen \& Tung, 2014; Han, 2015); however, there is no widespread agreement on which set of variables (the original TPB or morality variables) has greater explanatory power in relation to the ERBs of tourists. The findings of Han (2015) suggested that moral obligation has a greater impact on visitors' behavioural intentions toward staying in green hotels, while Chen and Tung (2014) asserted that the TPB variables had higher explanatory power than the variables reflecting morality.

In response to the critical research gaps discussed above, this paper followed two specific objectives: (1) Develop and empirically validate an extended TPB model through the perspective of the broken windows theory. In particular, this study seeks to investigate the role of perceived environment quality as an antecedent of the TPB components toward ERBs. (2) Compare and contrast the relative importance of original TPB variables and morality variable in explicating the formation of tourists' ERBs.

\section{Literature review}

\subsection{The broken windows effect}

The broken windows theory originated from criminology research, which was mainly applied to determine neighbourhood disorder (Wilson \& Kelling, 1982). According to the broken windows theory, a neighbourhood's physical appearance e.g. broken windows, litters, graffiti, and abandoned cars, sends messages to individuals that disorder behaviours are acceptable as the norm (Lang et al., 2010). While the broken windows 
effect refers to the hypothesis that little bad things left unresolved in the environment will attract more and bigger infractions within the community (Sampson \& Raudenbush, 2004). "The broken window" is just the first step, and other evidences of decay will gradually start to appear, such as more broken windows and more trash on the street (Lang et al., 2010). This theory can explain many other phenomena in daily life. For example, if there is one cigarette butt somewhere, slowly but surely, there will be more cigarette butts in the same area.

Emerging studies advocated that the use of broken windows effect should be extended beyond disorder behaviour and the context of neighbourhood, to any situation in which the environment quality may affect what behaviours individuals deem acceptable (Grimes, Marquardson, \& Nunamaker, 2014; Lefebvre, Pestieau, Riedl, \& Villeval, 2015). In the context of online environment, Grimes et al. (2014) indicated that low quality website, analogous to a neighbourhood with broken windows and litters everywhere, discourage online users from behaving securely. The findings of Lefebvre et al.'s (2015) research also assured the broken windows effect on tax evasion, revealing that individuals feel less committed to honesty if they observe bad examples of tax behaviour. Accordingly, we can presume, in the tourism context, when visitors perceived a poor environmental quality of a scenic area (e.g. garbage and litters), the broken windows effect may work, as the signs of littering in the scenic area likely induce more littering and fewer environmentally responsible behaviours. Inversely, if the ecological environment of the scenic area is good, visitors tend to maintain this environment, rather than destroy it. That is, as suggested in the broken windows theory (Lang et al., 2010), tourists' environmentally responsible behaviours (ERBs) may be triggered through signals conveyed by a scenic area's environment quality. However, information is limited in the extant research regarding whether perceived environment quality may have a significant influence on tourists' beliefs and attitudes towards ERBs in a scenic tourism area, suggesting further research is needed.

\subsection{Conceptualizing the broken windows theory within the TPB model}

The theory of planned behaviour (TPB), which was originally proposed by Ajzen (1985), is a well-known social psychology approach that focuses on how to motivate people to perform a behaviour of interest (Ajzen, 1991, 2015). The TPB has been successfully applied in determining human behaviours in a number of areas, including tourists' environmentally responsible behaviours (Brown et al., 2010; Han, 2015; Han, Hsu, \& Sheu, 2010; Powell \& Ham, 2008; Wu et al., 2013). According to the TPB framework, an individual's intention to engage in an action is jointly determined by his/her attitude, subjective norms, and perceived behavioural control (Ajzen, 1991). In this study, attitude refers to the degree to which a tourist holds a favourable or an unfavourable evaluation of environmentally responsible behaviours (ERBs) at a tourism destination. Subjective norms refer to a tourist's perceived social pressure to engage in or not engage in ERBs at tourism destination. Perceived behavioural control refers to the perceived ease of performing ERBs at a tourism destination. The appropriateness of the TPB components (attitude, subjective norm and perceived behavioural control) in explicating the formation 
of the ERBs have been validated in considerable research (Han et al., 2010; Wu et al, 2013). In attempt to enhance the efficacy of the TPB model in predicting ERBs, some studies extended the TPB components by incorporating theories and concepts such as norm-activation model (Abrahamse et al., 2009) and environmental value (Goh et al., 2017). Yet, these studies mostly focused on the extension of the TPB variables and less attention has been paid to the antecedent of the components of the TPB model (Chen \& Tung, 2014). In addition, current commentaries of the TPB pointed out that the focus on the changes in belief (i.e. interpretive strategy) was not sufficient to bring changes in the components of TPB, and contextual factors (i.e. surrounding environment) should be taken into consideration (Ajzen, 2015; Conner, 2015).

The broken windows theory suggests that a place's environment condition is sending contextual signals to individuals about which behaviours are acceptable and normative, which further influences individuals' behaviours (Lang et al., 2010). As such, the broken windows theory may provide a new perspective with which to understand the formation of individuals' ERBs. Places that are perceived as being environmentally pleasing are more likely to be appreciated and protected than the places that are not perceived as being environmentally pleasing (Uzzell \& Badenas, 2002). A good scenic environment can enhance the value of individuals' evaluations of ERBs, thereby promoting active attitudes towards environmental conservation (Scannell \& Gifford, 2010). In contrast to this, as supposed in the broken windows theory (Wilson \& Kelling, 1982), if the tourism destination is perceived as being dirty and disordered, tourists may undervalue their ERBs, thereby contributing to a worse ecological environment.

Apart from the influence on attitudes, broken windows theory might also imply an association between environment quality and subjective norm. Subjective norm in the TPB model refers to the social pressure that an individual perceives to perform or not to perform a certain behaviour, which comes from the social norms determined by other people (Ajzen, 1991; Han, 2015). According to the broken windows theory (Lang et al., 2010), when people observe the physical environment of a neighbourhood with graffiti and litters everywhere, they may deem environmental damage behaviours (e.g. littering) are acceptable or even as a social norm in this neighbourhood. Conversely, a good quality environment prompts people to have a strong sense of a pro-environmental social norm, which in turn leads to the intentions to maintain their good-quality environment (Uzzell $\&$ Badenas, 2002). People tend to engage in ERBs in a neighbourhood when they perceive the environment of the neighbourhood as being good quality, thereby fostering an atmosphere conducive to environmental protection (Scannell \& Gifford, 2010; Uzzell \& Badenas, 2002). Thus, in the case of tourism, we can presume that a better-maintained landscape would generate stronger subjective norm regarding ERBs.

Tourists' perceived behavioural control refers to the personal assessment of one's ability to carry out a behaviour (Ajzen, 1991), which is also influenced by circumstantial constraints (Miller et al., 2015; Zhang et al., 2016). As indicated in research on the broken windows theory, a chaotic environment discourages individuals from behaving prosocially (Lefebvre et al., 2015). In the context of tourism, the physical environment of a scenic area may hinder or facilitate a tourist's assessment of his/her ability to perform ERBs. For example, the availability of recycling infrastructure might encourage tourist's 
recycling behaviour at a tourism destination, while a lack of requisite infrastructure could impede the ability of tourists to implement environmental friendly behaviour (Miller et al., 2015). In other words, the quality of the physical environment can have an influence on tourists' perceived behavioural control towards ERBs. The higher the quality of a scenic area environment is, the more likely tourists will perceive conserving the environment as being easy and effective. Based on the preceding arguments, we proposed that perceived environment quality is the antecedent of the TPB variables and developed these hypotheses (see Figure 1), as follows:

H1. Tourists' perceived environment quality positively affects their attitudes in regard to engaging in ERBs.

H2. Tourists' perceived environment quality positively affects subjective norms in regard to engaging in ERBs.

H3. Tourists' perceived environment quality positively affects their perceived behavioural control in regard to engaging in ERBs.

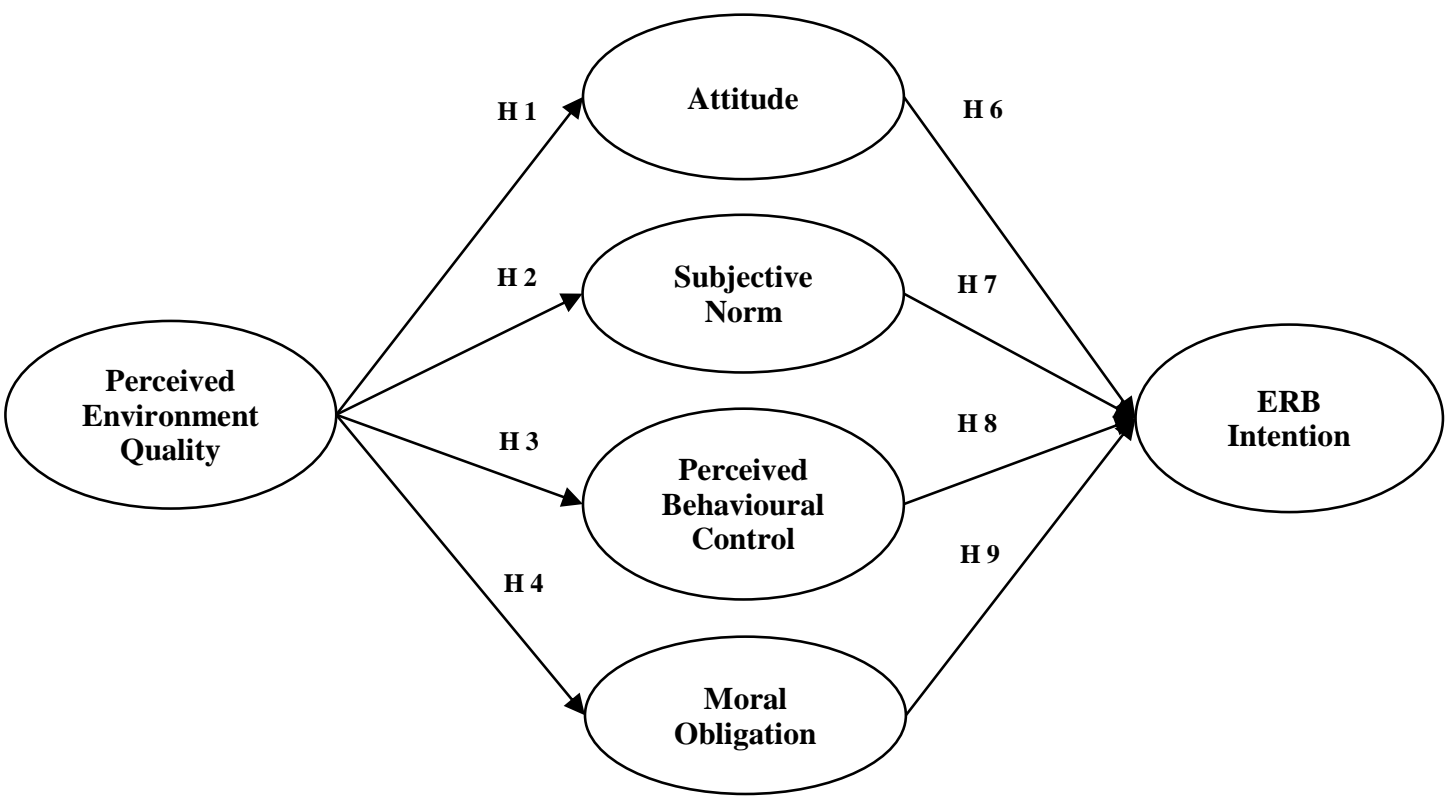

Figure 1. Conceptual model

Moral obligation has been widely investigated as a prominent predictor of pro-social behaviours (e.g. ERBs), which refers to people's sense of obligation to perform a certain action morally when facing with an ethical situation (Chen \& Tung, 2014; Dolnicar \& Leisch, 2008; Han, 2015; Kaiser \& Shimoda, 1999). Both Schwartz's (1977) normactivation model (NAM) and Stern et al.'s (1999) value-belief-norm (VBN) theory suggest that whether to engage in an altruistic behaviour is determined by an individual's moral obligation, and moral obligation is determined by the activation step. In Schwartz's NAM (1977), the activation step involves with a specific action environment in which 
moral obligation is constructed to reflect the expectations that individuals hold for themselves. It is possible that the perceived quality of an environment is positively related to people's own expectations as well as the generation of moral obligation. As the broken windows theory suggests, individuals feel less committed to morality if they observe a low level of the compliance of pro-social behaviours (Grimes et al., 2014; Lefebvre et al., 2015). We can infer that, in the case of tourism, when the perceived scenic environment is good, tourists' pro-environmental expectations for themselves tend to be activated, thus prompting a heightened moral obligation towards environment conservation. Accordingly, we developed the following hypothesis:

H4. Tourists' perceived environment quality positively affects their moral obligation in regard to engaging in ERBs.

According to the principle of reciprocal determinism, individual's behaviour results from both environmental and attitudinal factors, rather than from either factor alone (Bandura, 1977). Contextual factors (e.g. physical environment) may influence people's ERBs through psychosocial factors, such as attitudes and moral obligation (Steg \& Vlek, 2009; Stern, 1999; Thøgersen, 2005). Prior research using the TPB framework states that environmental variables (e.g. perceived safety and neighbourhood aesthetics) indirectly predict individual's leisure walking behaviour through the TPB variables (Lee \& Shepley, 2012). Specifically, the more positive perceptions people have of the environment, the greater their attitudes and perceived behavioural control will be towards the intention to engage in leisure walking. Although the positive link between environmental concern, the extended TPB variables (including moral obligation), and intention of ERBs has been determined in emerging tourism research (Chen \& Tung, 2014), the mediating effects of the extended TPB variables in linking perceived environment quality and intention of ERBs need to be further delved into. As previously discussed, tourist's perceived environment quality may have positive influence on the original TPB components as well as moral obligation. Tourists who perceive the environment of a tourism area as high quality are likely to have high level of attitudinal variables towards ERBs. Consequently, perceived environment quality that manifested through the TPB variables and morality variables would prompt tourists to the engage in ERBs in the tourism area. Based on the above arguments, we posited that:

H5. The TPB variables and moral obligation mediate the relationship between perceived environment quality and tourists' ERBs.

\subsection{Extend the TPB model with moral considerations}

Tourism and hospitality literature has largely verified that attitude, subjective norms, and perceived behavioural control all have significant and direct impacts on tourists' behavioural intentions (Han et al., 2010; Hsu \& Huang, 2012). Empirical evidence has also shown in recent studies regarding ERBs (Chen \& Tung, 2014; Han, 2015; Han et al., 2017) that individuals, attitudes, subjective norms, and perceived behavioural control 
significantly and directly influence a tourist's intention to engage in ERBs (e.g. visiting a green hotel). It has been demonstrated that, the more favourable the attitudes and subjective norms in question, and the greater the behavioural control perceived by tourists, the stronger tourists' willingness to engage in environmental friendly activities are (Han, 2015). Nevertheless, it seems that the effects of these TPB components on predicting ERBs vary across different studies. Findings from Hsu and Huang (2012) suggest that subjective norms have a greater influence on behavioural intention than perceived behavioural control and attitude, whereas Han et al. (2017) indicated that attitude and subjective norms are more decisive in encouraging tourists' ERBs. Drawing on the preceding arguments, we proposed the following hypotheses:

H6. Tourists' attitudes positively affect their intention to engage in ERBs.

H7. Tourists' subjective norms positively affect their intention to engage in ERBs.

H8. Tourists' perceived behavioural control positively affects their intention to engage in ERBs.

Schwartz's (1977) NAM and Stern et al.'s (1999) VBN take a distinct perspective from the TPB by focusing on moral considerations, in which moral obligation isdefined as a personal norm related to performing specific actions (Schwartz \& Howard, 1981; Stern et al., 1999). Both the NAM and the VBN consider moral obligation as the basis of people's intention to engage in ERBs (Chen \& Tung, 2014; Han, 2015). In the tourism literature, strong empirical evidences showed a positive association between tourists' moral obligation and his/her intention to perform ERBs (Han, 2015). The higher the degree of an individual's moral obligation, the more likely he or she would conduct proenvironmental actions (Chen \& Tung, 2014). In this study, tourists' moral obligation refers to the sense of obligation to engage in environmentally responsible actions in a tourism destination.

Increasing efforts have been exerted to extend the TPB by including a consideration of moral obligation, demonstrating the importance of moral-normative influences in regard to ERBs (Chen \& Tung, 2014; Han et al., 2017). Tourists' moral obligations affect his or her behavioural intentions independent of the original TPB variables (i.e., attitudes, subjective norms, and perceived behavioural control). Additionally, prior research revealed that when adding moral consideration to extend the TPB model, the extended model would have a better explanation power for behaviours of interest (Ajzen, 1991; Harland et al., 1999). Some studies have examined both the role of the original TPB variables and that of morality variables in predicting ERBs (Abrahamse et al., 2009; Chen \& Tung, 2014). However, little is known about whether or not the TPB components or moral considerations could have a higher level of explanatory power in regard to tourists' intention to engage in ERBs. Based on the literature review, the following was posited:

H9. Tourists' moral obligation positively affects their intention to engage in ERBs. 


\section{Methodology}

\subsection{Research instruments}

The survey questionnaire used in this study consists of two major parts: items that measured the perceived environment quality, attitudes, subjective norms, perceived behavioural control, moral obligations, and environmentally responsible behavioural intentions of tourists, and questions designed to obtain respondents' background information. All the items for the constructs were substantiated by a detailed analysis of relevant literature, and measures that were originally developed in English were translated into Chinese and then back translated to ensure content validity (Brislin, 1980). All items for the constructs were examined on a five-point Likert-type scale, ranging from "strongly disagree" (1) to "strongly agree" (5).

In order to assess tourists' perceived environment quality, we selected nine items based on the standard of the national 5A class scenic spot. The items selected were proposed by the China National Tourism Administration (CNTA, http://www.cnta.gov.cn/), including: "I think this scenic area is very clean", "I think the public toilets in this scenic area are very clean", "I think the air quality of this scenic area is pretty good", "I think there is little noise in this scenic area", "I think the water quality of this scenic area is very good", "I think the eco-landscapes of this scenic area are protected pretty well", "I think the greening efforts of this scenic area are good", "I think the constructions in this scenic area harmonize with the natural environment within the area", and "I think this scenic area harmonizes with its surrounding environment".

Four items adapted from Ajzen (2006) and Han et al. (2015) measured tourists' attitudes towards environmentally responsible behaviours, which assessed tourists' beliefs that engaging in ERBs is beneficial, pleasant, wise, and desirable.

The following three items provided a measure of subjective norms (Han et al., 2010): "Most people who are important to me think I should take actions to protect the environment in this scenic area", "Most people who are important to me would want me to protect the environment in this scenic area", and "People whose opinions I value would prefer that I engage in environmental protection in this scenic area".

Perceived behavioural control was measured by four items adapted from Ajzen (1991) and Han et al. (2010), including "Whether or not I take actions to protect the environment in this scenic area is completely up to me", "I am confident that, if I want to, I can protect the environment in this scenic area", "I have the resources, time, and opportunities to engage in environmental protection in this scenic area", and "For me, protecting the environment in this scenic area is easy".

The three items constructed by Onwezen et al. (2013) were adapted to measure tourists" moral obligation. They are "I feel a moral obligation to protect the environment", "Due to my own values or principles, I feel an obligation to behave in an environmentally friendly way", and "I feel it is important that people in general protect the environment".

For the tourists' environmentally responsible behavioural intentions, the findings presented by Ramkissoon et al. (2013) were adapted in this study, including: "I am willing to learn how to protect the environment in this scenic area", "I am willing to tell my 
friends and relatives not to damage the environment in this scenic area", "I would volunteer to reduce my use of a favourite spot in this scenic area if it needs to recover from environmental damage", "I would volunteer my time to projects that help this scenic area", "I am willing to write letters in support of this scenic area", "I am willing to participate in public activities to protect the environment in this scenic area", and "I am willing to donate my money to support environmental protection of this scenic area".

\subsection{Pilot test}

A pilot test was conducted in November 2015. A total of 156 usable questionnaires were returned. The Cronbach's alphas, correlation coefficients, factor loadings, skewness, kurtosis, and average variance extracted (AVE) were examined to assess all the items for the constructs. According to Parasuraman, Zeithaml, and Berry (1988), whether or not the exclusion of an item improves the corresponding alpha value and its corrected itemto-total correlation were the criteria used in deciding whether to eliminate an item. Additionally, we invited four academic experts specializing in ecotourism and four tourists who have been to ecotourism destinations to provide comments on the questionnaire items. Six items were discarded in response to the exclusion criteria and the experts' opinions. After the purifying measures had been carried out, the alpha coefficients of all the constructs were above 0.7, indicating good internal reliability (Nunnally \& Bernstein, 1994). All standardized factor loadings were greater than 0.7 and the average variance extracted (AVE) for each construct exceeded 0.5, confirming the convergent validity (Hair et al., 2010). Based on the results of the pilot test and feedback from both academic experts and tourists, 21 items were retained and the final version of the survey instrument was developed. The final survey questionnaire can be found in Appendix 1.

\subsection{Sampling and procedure}

The final survey was administered in March, 2016. Data were collected at two wellknown ecotourism sites in China: Huan Xisha ecological park and Baiyun Mountain. A convenience sampling method was employed to collect data on these two sites. Huan Xisha ecological park is located in the southwest of China and has an approximate land area of 32.3 hectares. The ecological park offers opportunities for visitors to get close to the nature and wildlife, particularly the egrets there. As an important environmental education base in China, Huan Xisha ecological park, which attracts thousands of visitors every year, has recently completed a refurbishment of its environmental interpretation services and activities. Another study site, Baiyun Mountain, is regarded as being the "green lung" of Guangzhou, which is located in South China. Baiyun Mountain is a national grade-AAAAA scenic area in China and is home to many endemic species.

Considering the requirements of structural equation modelling (SEM), in which one measurement needs 10 observations, the minimum sample size should be 210 for the 21 items in this study. A target of at least 160 usable questionnaires per site was set and a total of 307 completed questionnaires were returned, indicating a response rate of $95.93 \%$. Among the 307 respondents, $43.97 \%$ were male and $56.03 \%$ were female. In terms of age, 
more than half of the respondents $(65.8 \%)$ were between 19 and 30 years old, while $26.38 \%$ were aged between 31 and 45. As for the education levels of the respondents, 59.2\% held a bachelor's degree or higher and $40.8 \%$ had a secondary-level education or below. Among all of the respondents, 66.12\% earned less than 5000RMB (\$803.90) per month, while $33.88 \%$ earned more than 5001RMB (\$803.90). Since, at the time of data collection, the exchange rate was about $6.22 \mathrm{RMB}=\mathrm{US} \$ 1.00,5000 \mathrm{RMB}$ per month equates to $\$ 803.90$ per month.

\subsection{Data analysis}

The descriptive statistics and the correlations between factors were performed using SPSS 22.0. The quality of the measurement was confirmed through exploratory factor analysis (EFA) and confirmatory factor analysis (CFA). The model fit and the reliability and validity of the constructs were examined using Amos 17.0 software. To test the research model, SEM was employed to assess the relationships among the latent constructs. By using the PROCESS macro for SPSS (Hayes, 2013), the multiple mediation effects of the extended TPB model were evaluated.

Due to concerns regarding measurement error and common method bias, Harman's single factor test was used to evaluate common method variance in this study (Podsakoff, MacKenzie, Lee, \& Podsakoff, 2003). The logic underlying this approach is that, if common method bias poses a serious threat, a single latent factor should emerge from a factor analysis. We loaded all of the items into an exploratory factor analysis (EFA) to examine the unrotated factor solution, using principal-component factor analysis. In the model, the first six factors accounted for $74.29 \%$ of the variance, among which the first factor accounted for $34.97 \%$ of the variance, indicating that common method bias was not a serious threat in this sample.

\section{Results}

\subsection{Measurement model}

To examine whether or not the data fit the measurement model, we conducted a CFA to assess the measurement quality (Hair et al., 2010). Upon the results of the CFA, the reliability and validity of the constructs were confirmed (see Table 1). The Cronbach's alpha values for the latent constructs all exceeded the benchmark of 0.70 (Nunnally \& Bernstein, 1994), ranging from 0.783 to 0.911 . The construct's composite reliability values ranged from 0.792 to 0.912 , suggesting a good level of reliability in regard to all of the constructs. All standardized factor loadings are significantly greater than the accepted threshold of 0.50, and most of the average variance extracted (AVE) values exceeded 0.50 except in the case of one factor, namely, perceived environment quality(PEQ). Notwithstanding, PEQ's Cronbach's alpha and composite reliability values exceeded the recommended threshold, suggesting the AVE value of 0.499 not a serious threat to the validity of PEQ. In addition to this, discriminant analysis was assessed by comparing the shared variance between each pair of constructs against the minimum of the AVE (Fornell \& Larcker, 1981). The results showed that all the square roots of the 
AVE on the diagonal were higher than the inter-correlations between the corresponding latent constructs (see Table 2), suggesting good discriminant validity (Fornell \& Larcker, 1981; Hair et al., 2010).

Table 1. Confirmatory factor analysis $(\mathrm{N}=307)$

\begin{tabular}{|c|c|c|c|c|}
\hline Items & $\begin{array}{l}\text { Factor } \\
\text { loading }\end{array}$ & AVE & $\begin{array}{l}\text { Composite } \\
\text { reliability }\end{array}$ & $\begin{array}{l}\text { Cronbach's } \\
\text { alpha }\end{array}$ \\
\hline \multicolumn{5}{|l|}{ Attitude } \\
\hline beneficial & 0.855 & & & \\
\hline pleasant & 0.866 & 0.717 & 0.910 & 0.907 \\
\hline wise & 0.813 & & & \\
\hline desirable & 0.851 & & & \\
\hline \multicolumn{5}{|l|}{ Subjective norm } \\
\hline who are important to me think I should & 0.670 & & & \\
\hline who are important to me would want me to & 0.944 & 0.699 & 0.872 & 0.860 \\
\hline whose opinions I value would prefer & 0.870 & & & \\
\hline \multicolumn{5}{|l|}{ Perceived behavioural control } \\
\hline confident that if I want, I can & 0.704 & & & \\
\hline have resources, time, and opportunities & 0.733 & 0.560 & 0.792 & 0.783 \\
\hline protect environment in this area is easy & 0.805 & & & \\
\hline \multicolumn{5}{|l|}{ Moral obligation } \\
\hline I feel a moral obligation to protect & 0.886 & & & \\
\hline Because of my own values/principles & 0.830 & 0.775 & 0.912 & 0.911 \\
\hline I feel it is important & 0.923 & & & \\
\hline \multicolumn{5}{|l|}{ ERB intention } \\
\hline I would volunteer my time to projects & 0.866 & & & \\
\hline willing to write letters in support & 0.902 & 0.589 & 0.848 & 0.846 \\
\hline willing to participate in public activities & 0.694 & & & \\
\hline willing to donate my money to support & 0.559 & & & \\
\hline \multicolumn{5}{|l|}{ Perceived environment quality } \\
\hline I think this scenic area is very clean & 0.517 & 0.499 & 0.795 & 0.787 \\
\hline the eco-landscapes are protected pretty well & 0.719 & & & \\
\hline $\begin{array}{l}\text { the greening efforts of this scenic area are } \\
\text { good }\end{array}$ & 0.814 & & & \\
\hline $\begin{array}{l}\text { the constructions in this scenic area } \\
\text { harmonized with the natural environment }\end{array}$ & 0.740 & & & \\
\hline
\end{tabular}

Note: $\mathrm{a} . \mathrm{AVE}=$ average variance extracted $\mathrm{b} . \mathrm{ERB}=$ environmentally responsible behaviour 
Table 2. Correlations among variables

\begin{tabular}{|c|c|c|c|c|c|c|}
\hline & ATT & SN & $\overline{P B C}$ & MO & ERBI & $\begin{array}{l}\text { PEQ } \\
\end{array}$ \\
\hline ATT & $(0.847)$ & & & & & \\
\hline SN & $0.299^{* *}$ & $(0.836)$ & & & & \\
\hline PBC & $0.405^{* *}$ & $0.252^{* *}$ & $(0.762)$ & & & \\
\hline MO & $0.594^{* *}$ & $0.457^{* *}$ & $0.408^{* *}$ & $(0.880)$ & & \\
\hline ERBI & $0.464^{* *}$ & $0.480^{* *}$ & $0.339^{* *}$ & $0.494^{* *}$ & $(0.767)$ & \\
\hline PEQ & $0.369^{* *}$ & $0.310^{* *}$ & $0.268^{* *}$ & $0.389^{* *}$ & $0.356^{* *}$ & $(0.707)$ \\
\hline
\end{tabular}

Note: $\mathrm{a} .{ }^{*} \mathrm{p}<0.05,{ }^{* *} \mathrm{p}<0.01 \mathrm{~b}$. The numbers enclosed in parentheses and presented diagonally indicate the squared root of the AVEs. c. ATT=Attitude, $\mathrm{SN}=$ Subjective norm, $\mathrm{PBC}=$ Perceived behavioural control, $\mathrm{MO}=$ Moral obligation, $\mathrm{ERBI}=$ environmentally responsible behaviour intention, $\mathrm{PEQ}=$ Perceived environment quality

In assessing the measurement model, two different fit indices were employed. It is agreed that a chi-square test $(\chi 2)$ with degrees of freedom should be employed as a guide, instead of an absolute index of model fit, due to its sensitivity to sample size (Anderson $\&$ Gerbing, 1982). Thus, we also assessed the comparative fit index (CFI), the TuckerLewis index (TLI), and the root mean square error of approximation (RMSEA), which are generally unaffected by the sample size. According to Byrne (1998), to represent a good model fit, the RMSEA should be less than 0.08, whereas the GFI, CFI, and TLI should be higher than 0.90. Based on the above rules, the CFA results showed that the model was a good fit, with $\chi 2 / \mathrm{df}=1.858, \mathrm{RMSEA}=0.053, \mathrm{CFI}=0.959$, and TLI $=0.946$, all of which are within the recommended range.

\subsection{Structural model}

In regard to validating the measurement model, the research hypotheses of this study were examined using an SEM approach. The structural model was characterized by the indices, $\chi 2 / \mathrm{df}=2.558$, indicating an acceptable level of model fit. The results of the other indices also supported the good fit of the model: RMSEA $=0.071, \mathrm{CFI}=0.923$ and TLI $=0.911$. We therefore continued the analysis with hypothesis testing (see Figure 2). 


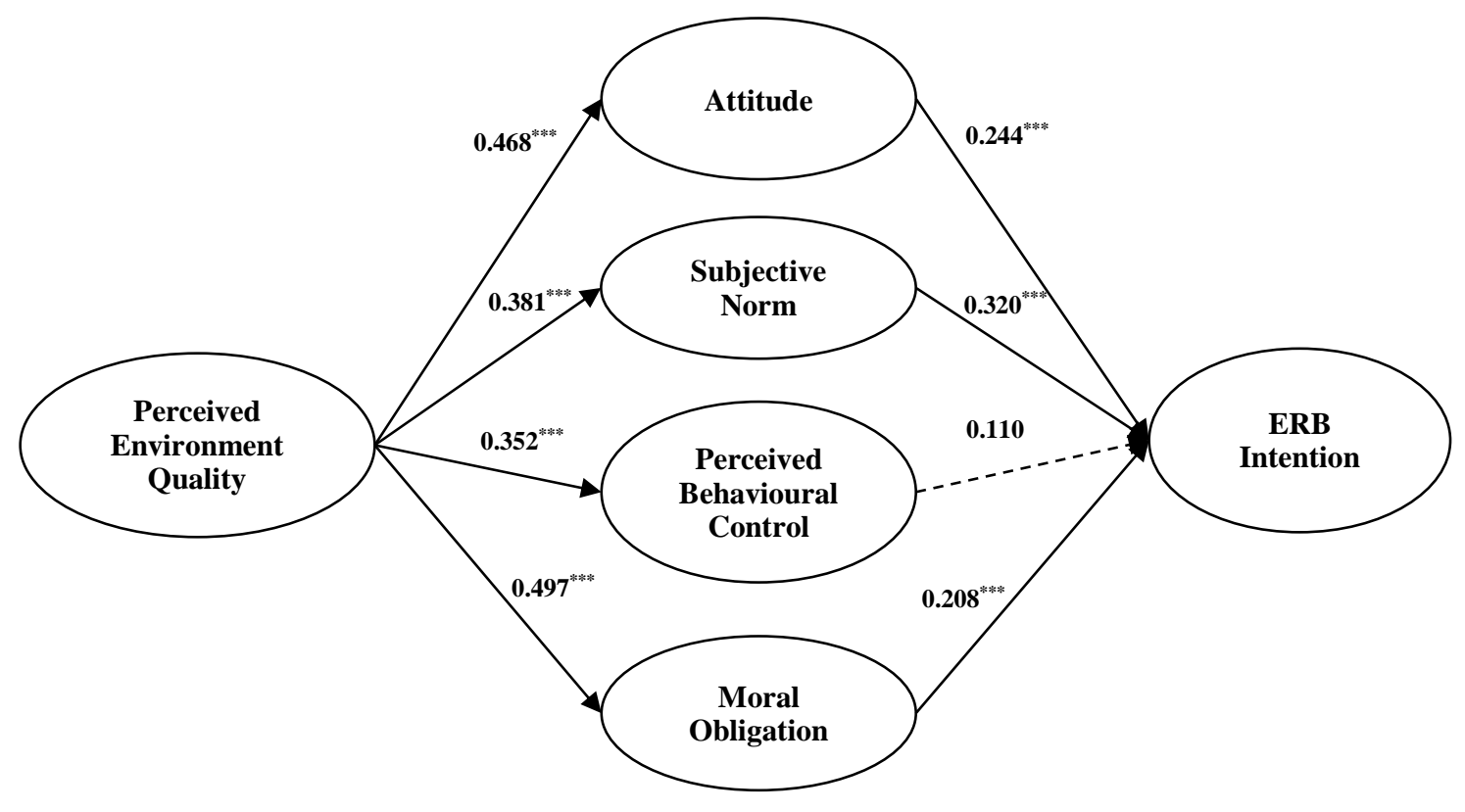

Note: ${ }^{*} \mathrm{p}<0.05,{ }^{* *} \mathrm{p}<0.01,{ }^{* * *} \mathrm{p}<0.001$

Figure 2. Conceptual model results

All of the hypotheses, except for Hypothesis 8, were supported in their predicted directions, thereby empirically validating the model proposed in this study. First, we hypothesized a positive relationship between perceived environmental quality and attitude, subjective norm, perceived behavioural control, and moral obligation. The results of the hypothesis testing revealed that tourists' perceived environment quality directly and positively affects their attitude $(\beta=0.468, \mathrm{p}<.01)$, subjective norm $(\beta=$ $0.381, \mathrm{p}<.01)$, perceived behavioural control $(\beta=0.352, \mathrm{p}<.01)$, and moral obligation $(\beta=0.497, p<.01)$. The results suggested that the most affected factor was tourists' moral obligation, indicating that people's pro-social motives are more closely related to the perceived environment quality than the original TPB variables. As hypothesized, tourists' attitude $(\beta=0.244, \mathrm{p}<.01)$, subjective norm $(\beta=0.320, \mathrm{p}<.01)$, and moral obligation $(\beta=0.208, \mathrm{p}<.01)$ positively affected their environmentally responsible behavioural (ERB) intention, among which subjective norm was determined as the strongest predictor of ERB intention. Notably, tourists' perceptions of behavioural control $(\beta=0.110, p>.05)$ did not significantly influence their ERB intention on-site; thus, Hypothesis 8 was rejected. These results suggested that tourists' ERB intention is affected by both the original TPB variables and moral obligation, but more so by the original TPB variables.

\subsection{The multiple mediation analysis}

Bootstrapping is strongly recommended when examining the effects of multiple mediations (Preacher, Rucker, \& Hayes, 2007), wherein the null hypothesis regarding the direct effect should be rejected if zero lies outside the bootstrapped confidence intervals 
(CIs). The advantage of PROCESS macro for SPSS is that it not only allows researchers to test multiple mediators simultaneously but also includes bootstrapping to quantify the stability of the indirect effect (Hayes, 2013). This study used 5,000 bootstrapping resamples to generate $95 \% \mathrm{CIs}$ for one-tailed tests of the statistical significance. To test the multiple mediation effects of the extended TPB model, we employed PROCESS Model 4. Perceived environment quality was entered as the independent variable, tourist's ERB intention as the outcome variable, and the extended TPB components (attitude, subjective norm, perceived behavioural control, and moral obligation) as the mediators.

The test revealed that the direct effect of perceived environment quality (PEQ) on tourist's ERB intention was not significant $(\beta=0.067, \mathrm{SE}=0.053,95 \% \mathrm{CI}:-0.038$ to 0.173). There were significant indirect effects of perceived environment quality (PEQ) on ERB intention through the mediations of attitude $(\beta=0.063, \mathrm{SE}=0.021,95 \% \mathrm{CI}$ : 0.027 to 0.111 ), subjective norm $(\beta=0.078, \mathrm{SE}=0.023,95 \% \mathrm{CI}$ : 0.041 to 0.131 ), perceived behavioural control ( $\beta=0.019, \mathrm{SE}=0.013,95 \% \mathrm{CI}$ : 0.001 to 0.056$)$ and moral obligation ( $\beta=0.077, \mathrm{SE}=0.025,95 \% \mathrm{CI}$ : 0.035 to 0.135 ). As such, Hypothesis 5 was supported; the extended TPB variables significantly and simultaneously mediate the relationship between perceived environment quality and tourist's ERB intention.

Table 3. Test of the mediating effects of the extended TPB variables on the relationship between perceived environment quality and ERB intention

\begin{tabular}{cccccc}
\hline & & & & \multicolumn{2}{c}{ Bootstrapping 95\% CI } \\
\cline { 6 - 7 } & & $\beta$ & $S E$ & low & high \\
\hline Indirect effects & & & & & \\
Attitude & 0.0034 & 0.063 & 0.021 & 0.027 & 0.111 \\
Subjective norm & 0.0005 & 0.078 & 0.023 & 0.041 & 0.131 \\
Perceived behavioural control & 0.1010 & 0.019 & 0.013 & 0.001 & 0.056 \\
Moral obligation & 0.0019 & 0.077 & 0.025 & 0.035 & 0.135 \\
total & & 0.238 & 0.039 & 0.165 & 0.321 \\
Direct effect & & & & & \\
PEQ-ERBI & 0.209 & 0.067 & 0.053 & -0.038 & 0.173 \\
\hline
\end{tabular}

Note: a. ERBI=environmentally responsible behaviour intention, $\mathrm{PEQ}=$ Perceived environment quality

\section{Discussion and conclusion}

\subsection{Discussion}

Comprising the perspective of the broken windows theory, this study explored the contextualization of tourists' environmentally responsible behaviours (ERBs), based on the theory of planned behaviour (TPB), the norm-activation model (NAM) and the valuebelief-norm (VBN). Summarizing the results from the data analysis and hypothesis testing, this study assessed the antecedent role of perceived environment quality in 
affecting the extended TPB model (including attitude, subjective norm, perceived behavioural control, moral obligation, and ERBs intention). The findings lend support to the broken windows theory (Wilson \& Kelling, 1982), which suggests perceived environment quality (PEQ) has a significant effect on individuals' decisions to engage in ERBs. Specifically, the results of this study affirmed that the better the perceived scenic environment, the stronger the extended TPB variables are in regard to tourists' ERBs. Consistent with the broken windows effect, a dirty and messy environment leads to bad perceived environment quality (Lang et al., 2010), which, in turn, can discourage tourists' from performing pro-environmentally. As assumed in earlier sections, tourists' first impressions of a tourism destination are of great importance to his or her subsequent environmental behaviours, to the extent that they can have more of an impact on these behaviours than an early intervention from the destination management might.

Besides the significant predicting effect of perceived environment quality on the TPB components, the results of this research support the direct and positive influences of both the original TPB variables and morality variable on tourists' ERB intentions at destinations, coinciding with previous research (Chen \& Tung, 2014; Han, 2015). However, the relationship between tourists' perceived behavioural control and their ERB intentions was found insignificant, which is consistent with discussions regarding the weak link of perceived behavioural control and intention in prior studies (Eagly \& Chaiken, 1993; Bansal \& Taylor, 2002). In addition, the multiple mediation analysis affirms that the effect of perceived environment quality on tourist's intention to engage in ERBs is fully mediated by the extended TPB components (attitude, subjective norm, perceived behavioural control, and moral obligation). That is, the environment quality encourages or inhibits tourist's pro-environmental behaviours via attitudinal variables.

Unlike traditional viewpoints in previous studies (Abrahamse et al., 2009; Steg et al., 2005), the finding of this research indicates that tourists' ERBs are better explained by the original TPB components rather than morality variables. Although tourists' moral obligation does play a role in their ERBs, when it comes to common resources, such as scenic areas, people may believe that other tourists are enjoying the environment without contributing to the environment sustainability; therefore, the morality motivation has only a weak influence on tourists' actual ERBs (Frederiks, Stenner, \& Hobman, 2015). Additionally, when the relative criticalities among the driving motives of ERB intention were compared, subjective norm showed a greater level of importance, which concurs with findings from some previous research (Han et al., 2017; Wong \& Ahuvia, 1998). As Uzzell and Badenas (2002) asserted, social influence is a key factor to have a better understanding of environmental attitudes and behaviours, due to the social nature of human beings and the collective nature of environmental problems. The decisive role of subjective norm in promoting tourists' ERB intention also corresponds with the results of prior research regarding cultural differences (Lee \& Green, 1991; Wong \& Ahuvia, 1998), which suggested that subjective norm has stronger predicting power in Eastern Confucian societies (e.g. China and Korea).While attitude, as the determinant of intention, is more significant than other factors for Americans (Lee \& Green, 1991). A possible explanation for why Chinese tourists place greater importance on the anticipated reactions of others to their behaviours may be that they are prone to conform to social roles in regard to 
obtaining social identity and reducing social pressure.

Through theoretical and empirical analyses, the major conclusions of this study were made. First, based on the broken windows theory, a contextualized understanding of environmental behaviour is imperative. In the context of tourism, perceived environment quality plays as a significant antecedent of people's attitudinal factors towards ERBs. Second, compared to moral considerations, the original TPB variables are of greater importance in predicting tourists' ERBs, among which subjective norm showed a strong impact on Chinese tourists, whereas perceived behavioural control was not an effective antecedent of ERB intentions. Third, although there was no direct impact of environment quality on tourist's ERB intention, the extended TPB components, as multiple mediators, provide links between environment quality and tourist's intention to engage in ERBs.

\subsection{Theoretical and managerial implications}

From a theoretical viewpoint, this study extends the extant research by providing a richer picture of how tourists' environmentally responsible behaviour is shaped. Albeit proenvironmental behaviour has been a long-lasting topic in tourism literature, with considerable efforts devoted to its formation and precedents (Abrahamse et al., 2009; Chen \& Tung, 2014; Han, 2015; Han et al., 2017), the literature has just begun to understand the formation of pro-environmental behaviours by considering an individual's ERBs as contextualized behaviours. Based on the broken windows theory and the TPB framework, the current study refreshes the role of environment quality in tourism research: Instead of being as the outcome of attitudinal factors (e.g. the TPB components), environment can also be an antecedent of the attitudinal variables. Although prior tourism literature has so far neglected the impact of environment quality on pro-environmental attitudes (Chen \& Tung, 2014; Powell \& Ham, 2008; Kim et al., 2011), the results of this study affirmed that tourists' perceived environment quality is an important antecedent of the extended TPB model, demonstrating a successful application of the broken windows theory.

As posited in the broken windows theory, a poor scenic environment will lead to a worse scenic environment (Wilson \& Kelling, 1982; Lang et al., 2010). The findings of this research verified that the existing dirty and messy environment could send messages to tourists that environment damage behaviour at the destination in question is permissible while pro-environmental behaviour might be unavailing. On the contrary, the better the scenic environment is, the more likely a tourist is to engage in pro-environmental activities at a tourism destination. The current study validates the use of the broken windows theory in the ERBs formation research with empirical evidences. Such an endeavour is scant in the extant literature, but necessary in verifying and extending the application of the broken windows theory to tourism context.

This study also contributes to the accumulation of knowledge in the development of TPB model, by extending the original TPB model comprising the broken windows theory and moral considerations. Echoing the recent call of Ajzen (2015) to draw attention to the contextual factors (e.g. environment quality), this study examined the role of environmental quality as the antecedent of the TPB components concerning 
environmental behaviours. The findings of this research affirm that the broken windows effect may work at an early stage of the ERBs formation, by shaping the TPB components leading to ERBs. With the comparison of morality variable and the original TPB variables in affecting tourists' ERB intentions, the study provides insights into the TPB components. The findings reveal that the TPB variables (e.g., attitudes and subjective norms) are more meaningful in promoting tourists' environmentally responsible behaviours, while morality plays a small role in encouraging pro-environmental behaviours. This study also sheds light upon the importance of social influence in predicting Chinese tourists' environmental behaviours, reflecting a cultural influence.

From a practical standpoint, the findings of this study suggest several important managerial implications. The vital role of perceived scenic environment in encouraging tourists' pro-environmental intentions should be noted. According to the evidence presented in this research, if there is litter everywhere at a destination, a worse environment will follow; in contrast to this, if a tourist environment is perceived as being clean and nice, tourists are more likely to engage in efforts to conserve the good environment, rather than destroy it. Tourism managers should therefore consider providing a clean and enjoyable environment in the first place, which may motivate more and more tourists to engage in environmentally responsible behaviours. As we illustrated earlier, first impressions are more important than the following interventions of tourism management. After all, "if you do well, I will do well".

The findings of this research may also remind tourism managers to pay attention to social contexts. In order to cultivate an environmentally friendly social norm, tourism practitioners may consider organizing more events focused on sustainability, which can make tourists involved in conserving the environment in a tourist area more visible to others. The social pressure exerted by the knowledge that others are behaving in an environmentally responsible manner is helpful in encouraging tourists to follow such a social norm and behave in a more pro-environmental manner.

\subsection{Limitations and future research directions}

This study provides insights into the contextualization of environmental behaviours in tourism destinations, although it is limited to convenience sampling. Moreover, due to the difficulty of collecting data, only a few elderly people were sampled, which may have skewed the results. A more rigorous sampling method should be employed in future work. Although the AVE value for perceived environment quality (0.49) is a bit below the threshold value of 0.5 , the values of other indicators (e.g. Cronbach's alpha and composite reliability) assured a reasonable validity of perceived environment quality. Future studies may consider expanding the scope of data and validating the results across different contexts. The current study only determined perceived environment quality as the external factor, although the availability of infrastructure and other factors have been utilized in some prior studies. Other important contextual factors are encouraged in future research to further investigate how tourists' pro-environmental intentions are formulated. Furthermore, this study focused on individuals' behaviours, but motivating people to contribute to environmental conservation should be considered in regard to the group 
effect. Thus, future studies are required to expand this research perspective from the level of the individual to the level of the group.

\section{References:}

Abrahamse, W., Steg, L., Gifford, R., \& Vlek, C. (2009). Factors influencing car use for commuting and the intention to reduce it: A question of self-interest or morality? Transportation Research Part F: Traffic Psychology and Behaviour, 12(4), 317324.

Ajzen, I. (1985). From intentions to actions: A theory of planned behaviour. In Action control (pp. 11-39). Springer: Berlin Heidelberg.

Ajzen, I. (1991). The theory of planned behaviour. Organizational Behaviour and Human Decision Processes, 50(2), 179-211.

Ajzen, I. (2006). Constructing a theory of planned behaviour questionnaire. Retrieved fromhttps://scholar.google.com.hk/scholar?cluster=2195952169797129031\&hl= zh-CN\&as_sdt=0,5

Ajzen, I. (2015). The theory of planned behaviour is alive and well, and not ready to retire: a commentary on Sniehotta, Presseau, and Araújo-Soares. Health Psychology Review, 9(2), 131-137.

Anderson, J., \& Gerbing, D. (1982). Some Methods for Respecifying Measurement Models to Obtain Unidimensional Construct Measurement. Journal of Marketing Research, 19(4), 453-460.

Ballantyne, R., \& Packer, J. (2011). Using tourism free - choice learning experiences to promote environmentally sustainable behaviour: the role of post - visit 'action resources'. Environmental Education Research, 17(2), 201-215.

Ballantyne, R., Packer, J., \& Sutherland, L. A. (2011). Visitors' memories of wildlife tourism: Implications for the design of powerful interpretive experiences. Tourism Management, 32(4), 770-779.

Bandura, A. (1977). Social learning theory. Oxford, England: Prentice-Hall.

Bansal, H. S., \& Taylor, S. F. (2002). Investigating interactive effects in the theory of planned behaviour in a service-provider switching context. Psychology \& Marketing, 19(5), 407-425. 
Brislin, R. W. (1980). Cross-Cultural Research Methods. In I. Altman, A. Rapoport, \& J. F. Wohlwill (Eds.), Environment and Culture (pp. 47-82). Boston, MA: Springer US.

Brown, T. J., Ham, S. H., \& Hughes, M. (2010). Picking up litter: An application of theory-based communication to influence tourist behaviour in protected areas. Journal of Sustainable Tourism, 18(7), 879-900.

Byrne, B.M. (1998), Structural Equation Modeling with LISREL, PRELIS and SIMPLIS: Basic Concepts, Applications and Programming. Mahwah, New Jersey: Lawrence Erlbaum Associates.

Chen, M.F., \& Tung, P.J. (2014). Developing an extended Theory of Planned Behaviour model to predict consumers' intention to visit green hotels. International Journal of Hospitality Management, 36, 221-230.

Conner, M. (2015). Extending not retiring the theory of planned behaviour: a commentary on Sniehotta, Presseau and Araújo-Soares. Health Psychology Review, 9(2), 141145.

Dolnicar, S., \& Leisch, F. (2008). An investigation of tourists' patterns of obligation to protect the environment. Journal of Travel Research, 46(4), 381-391.

Eagly, A. H., \& Chaiken, S. (1993). The Psychology of Attitudes. Orlando, FL, US: Harcourt Brace Jovanovich College Publishers.

Fornell, C., \& Larcker, D. (1981). Evaluating Structural Equation Models with Unobservable Variables and Measurement Error. Journal of Marketing Research, 18(1), 39-50.

Frederiks, E. R., Stenner, K., \& Hobman, E. V. (2015). Household energy use: Applying behavioural economics to understand consumer decision-making and behaviour. Renewable and Sustainable Energy Reviews, 41, 1385-1394.

Goh, E., Ritchie, B., \& Wang, J. (2017). Non-compliance in national parks: An extension of the theory of planned behaviour model with pro-environmental values. Tourism Management, 59, 123-127.

Grimes, M. G., Marquardson, J., \& Nunamaker, J. F. (2014). Broken windows, bad passwords: Influencing secure user behavior via website design. In 20th Americas Conference on Information Systems, AMCIS 2014 Association for Information Systems.

Hair, J. F., Anderson, R. E., Babin, B. J., \& Black, W. C. (2010). Multivariate data analysis: A global perspective (Vol. 7). Upper Saddle River, NJ: Pearson. 
Han, H. (2015). Travelers' pro-environmental behaviour in a green lodging context: Converging value-belief-norm theory and the theory of planned behaviour. Tourism Management, 47, 164-177.

Han, H., Hsu, L. T. J., \& Sheu, C. (2010). Application of the theory of planned behaviour to green hotel choice: Testing the effect of environmental friendly activities. Tourism Management, 31(3), 325-334.

Han, H., Meng, B., \& Kim, W. (2017). Emerging bicycle tourism and the theory of planned behaviour. Journal of Sustainable Tourism, 25(2), 292-309.

Harland, P., Staats, H., \& Wilke, H. A. (1999). Explaining proenvironmental intention and behaviour by personal norms and the theory of planned behaviour. Journal of Applied Social Psychology, 29(12), 2505-2528.

Hayes, A. F. (2013). Introduction to mediation, moderation, and conditional process analysis: A regression-based approach. Guilford Press: New York.

Hsu, C. H., \& Huang, S. (2012). An extension of the theory of planned behaviour model for tourists. Journal of Hospitality \& Tourism Research, 36(3), 390-417.

Iacobucci, D., Saldanha, N., \& Deng, X. (2007). A Meditation on Mediation: Evidence That Structural Equations Models Perform Better Than Regressions. Journal of Consumer Psychology, 17(2), 139-153.

Kaiser, F. G., \& T. A. Shimoda. (1999). Responsibility as a Predictor of Ecological Behaviour. Journal of Environmental Psychology, 19 (3): 243-53.

Kim, A. K., Airey, D., \& Szivas, E. (2011). The multiple assessment of interpretation effectiveness: Promoting visitors' environmental attitudes and behaviour. Journal of Travel Research, 50(3), 321-334.

Lang, D. L., Salazar, L. F., Crosby, R. A., DiClemente, R. J., Brown, L. K., \& Donenberg, G. R. (2010). Neighbourhood environment, sexual risk behaviours and acquisition of sexually transmitted infections among adolescents diagnosed with psychological disorders. American Journal of Community Psychology, 46(3-4), 303-311.

Lee, Y. K. (2016). Impact of government policy and environment quality on visitor loyalty to Taiwan music festivals: Moderating effects of revisit reason and occupation type. Tourism Management, 53, 187-196.

Lee, C., \& Green, R. T. (1991). Cross-Cultural Examination of the Fishbein Behavioural Intentions Model. Journal of International Business Studies, 22(2), 289-305. 
Lee, H. S., \& Shepley, M. M. (2012). Perceived neighborhood environments and leisuretime walking among Korean adults: An application of the theory of planned behaviour. HERD: Health Environments Research \& Design Journal, 5(2), 99110.

Lefebvre, M., Pestieau, P., Riedl, A., \& Villeval, M. C. (2015). Tax evasion and social information: an experiment in Belgium, France, and the Netherlands. International Tax and Public Finance, 22(3), 401-425.

Miller, G., \& Twining-Ward, L. (2005). Monitoring for a sustainable tourism transition: The challenge of developing and using indicators. Oxfordshire, UK: CABI.

Miller, D., Merrilees, B., \& Coghlan, A. (2015). Sustainable urban tourism: Understanding and developing visitor pro-environmental behaviours. Journal of Sustainable Tourism, 23(1), 26-46.

Nunnally, J. C., \& Bernstein, I. H. (1994). Psychological theory. New York, NY: MacGraw-Hill.

Onwezen, M. C., Antonides, G., \& Bartels, J. (2013). The Norm Activation Model: An exploration of the functions of anticipated pride and guilt in pro-environmental behaviour. Journal of Economic Psychology, 39, 141-153.

Parasuraman, A., Zeithaml, V. A., \& Berry, L. L. (1988). SERVQUAL: A MultipleItem Scale for Measuring Consumer Perceptions of Service Quality. Journal of Retailing, 64(1), 12-40. Retrieved from http://search.ebscohost.com/login.aspx?direct=true \&db=bth\&AN=6353339\&sit e=ehost-live

Pine, B. J., \& Gilmore, J. H. (1998). Welcome to the experience economy. Harvard Business Review, 76, 97-105.

Podsakoff, P. M., MacKenzie, S. B., Lee, J. Y., \& Podsakoff, N. P. (2003). Common method biases in behavioural research: a critical review of the literature and recommended remedies. Journal of Applied Psychology, 88(5), 879-903.

Powell, R. B., \& Ham, S. H. (2008). Can ecotourism interpretation really lead to proconservation knowledge, attitudes and behaviour? Evidence from the Galapagos Islands. Journal of Sustainable Tourism, 16(4), 467-489.

Preacher, K. J., Rucker, D. D., \& Hayes, A. F. (2007). Addressing moderated mediation hypotheses: Theory, methods, and prescriptions. Multivariate Behavioural Research, 42(1), 185-227. 
Ramkissoon, H., Graham Smith, L. D., \& Weiler, B. (2013). Testing the dimensionality of place attachment and its relationships with place satisfaction and proenvironmental behaviours: A structural equation modelling approach. Tourism Management, 36, 552-566.

Sampson, R. J., \& Raudenbush, S. W. (2004). Seeing disorder: Neighborhood stigma and the social construction of "broken windows". Social Psychology Quarterly, 67(4), 319-342.

Scannell, L., \& Gifford, R. (2010). The relations between natural and civic place attachment and pro-environmental behaviour. Journal of Environmental Psychology, 30(3), 289-297.

Steg, L., \& Vlek, C. (2009). Encouraging pro-environmental behaviour: An integrative review and research agenda. Journal of Environmental Psychology, 29(3), 309317.

Steg, L., Dreijerink, L., \& Abrahamse, W. (2005). Factors influencing the acceptability of energy policies: A test of VBN theory. Journal of Environmental Psychology, $25(4), 415-425$.

Stern, P. C. (1999). Information, incentives, and pro-environmental consumer behaviour. Journal of Consumer Policy, 22, 461-478.

Stern, P.C., Dietz, T., Abel, T., Guagnano, G.A., \& Kalof, L. (1999), A Value-BeliefNorm theory of support for social movements: The case of environmentalism. Human Ecology Review, 6(2), 81-97.

Sparks, P., \& Shepherd, R. (2002). The role of moral judgments within expectancy-valuebased attitude-behaviour models. Ethics \& Behaviour, 12(4), 299-321.

Schwartz, S. H. (1977). Normative Influences on Altruism. Advances in Experimental Social Psychology, 10, 221-279.

Schwartz, S. H., \& Howard, J. A. (1981). A normative decision-making model of altruism. J.P. Rushton (Ed.), Altruism and helping behaviour. Social, personality, and developmental perspectives, Erlbaum, Hillsdale, NJ (1981)

Thøgersen, J. (2005). How may consumer policy empower consumers for sustainable lifestyles? Journal of Consumer Policy, 28, 143-178.

Uzzell, D., Pol, E., \& Badenas, D. (2002). Place identification, social cohesion, and enviornmental sustainability. Environment and Behaviour, 34(1), 26-53.

Wilson, J. Q., \& Kelling, G. L. (1982). The police and neighborhood safety: Broken windows. Atlantic Monthly, 127(2), 395-407. 
Wong, N. Y., \& Ahuvia, A. C. (1998). Personal taste and family face: Luxury consumption in Confucian and Western societies. Psychology \& Marketing, 15(5), 423-441.

Wu, J., Huang, D., Liu, J., \& Law, R. (2013). Which factors help visitors convert their short-term pro-environmental intentions to long-term behaviours? International Journal of Tourism Sciences, 13(2), 33-56.

Wu, J. H., Li, S. H., \& Sung, W. Y. (2016). The study of perceived environment and its relation to senior citizen's physical activity behaviour intention. Journal of Business Research, 69(6), 2259-2264.

Zhang, Z., Zhang, Z., \& Law, R. (2014). Positive and negative word of mouth about restaurants: Exploring the asymmetric impact of the performance of attributes. Asia Pacific Journal of Tourism Research, 19(2), 162-180.

Zhang, S., Zhang, M., Yu, X., \& Ren, H. (2016). What keeps Chinese from recycling: Accessibility of recycling facilities and the behaviour. Resources, Conservation and Recycling, 109, 176-186. 


\section{Appendix 1. Survey questionnaire}

\section{Tourist Behaviour Survey}

\section{Dear visitor:}

We would like invite you to participate in a survey. The purpose of this study is to investigate tourist environmental responsible behaviour. The survey should take less than 15 minutes to complete.

Your participation is voluntary, but I hope you would help me. Please note that your responses will remain confidential.

Please feel free to contact us at (xxxx) should you have any questions.

The researchers,

Section1: Please indicate the extent of your agreement with the following statements:

1 =Strongly disagree, 2 = Disagree, 3 = Neutral, 4 = Agree, 5 = Strongly agree

\begin{tabular}{|l|l|l|l|l|l|l|}
\hline No. & Item. & $\begin{array}{l}\text { Strongly } \\
\text { disagree }\end{array}$ & Disagree & Neutral & $\begin{array}{c}\text { Agree } \\
\text { Strongly } \\
\text { agree }\end{array}$ \\
\hline 1 & $\begin{array}{l}\text { I think this scenic area is very } \\
\text { clean }\end{array}$ & 1 & 2 & 3 & 4 & 5 \\
\hline 2 & $\begin{array}{l}\text { I think the public toilets in this } \\
\text { scenic area are very clean }\end{array}$ & 1 & 2 & 3 & 4 & 5 \\
\hline 3 & $\begin{array}{l}\text { I think the air quality of this scenic } \\
\text { area is pretty good }\end{array}$ & 1 & 2 & 3 & 4 & 5 \\
\hline 4 & $\begin{array}{l}\text { I think there is little noise in this } \\
\text { scenic area }\end{array}$ & 1 & 2 & 3 & 4 & 5 \\
\hline 5 & $\begin{array}{l}\text { I think the water quality of this } \\
\text { scenic area is very good }\end{array}$ & 1 & 2 & 3 & 4 & 5 \\
\hline 6 & $\begin{array}{l}\text { I think the eco-landscapes of this } \\
\text { scenic area are protected pretty } \\
\text { well }\end{array}$ & 1 & 2 & 3 & 4 & 5 \\
\hline 7 & $\begin{array}{l}\text { I think the greening efforts of this } \\
\text { scenic area are good }\end{array}$ & 1 & 2 & 3 & 4 & 5 \\
\hline 8 & $\begin{array}{l}\text { I think the constructions in this } \\
\text { scenic area harmonize with the } \\
\text { natural environment within the } \\
\text { area }\end{array}$ & 1 & 2 & 3 & 4 & 5 \\
\hline 9 & $\begin{array}{l}\text { I think this scenic area harmonizes } \\
\text { with its surrounding environment }\end{array}$ & 1 & 2 & 3 & 4 & 5 \\
\hline
\end{tabular}


Section 2: Please indicate the extent of your agreement with the following statements:

1 =Strongly disagree, 2 = Disagree, 3 = Neutral, 4 = Agree, 5 = Strongly agree

\begin{tabular}{|l|l|l|l|l|l|l|}
\hline No. & Item & $\begin{array}{l}\text { Strongly } \\
\text { disagree }\end{array}$ & Disagree & Neutral & $\begin{array}{c}\text { Agree } \\
\text { Strongly } \\
\text { agree }\end{array}$ \\
\hline 1 & $\begin{array}{l}\text { I am willing to learn how to protect the } \\
\text { environment in this scenic area }\end{array}$ & 1 & 2 & 3 & 4 & 5 \\
\hline 2 & $\begin{array}{l}\text { I am willing to tell my friends and } \\
\text { relatives not to damage the environment } \\
\text { in this scenic area }\end{array}$ & 1 & 2 & 3 & 4 & 5 \\
\hline 3 & $\begin{array}{l}\text { I would volunteer to reduce my use of a } \\
\text { favourite spot in this scenic area if it } \\
\text { needs to recover from environmental } \\
\text { damage }\end{array}$ & 1 & 2 & 3 & 4 & 5 \\
\hline 4 & $\begin{array}{l}\text { I would volunteer my time to projects } \\
\text { that help this scenic area }\end{array}$ & 1 & 2 & 3 & 4 & 5 \\
\hline 5 & $\begin{array}{l}\text { I am willing to participate in public } \\
\text { activities to protect the environment in } \\
\text { this scenic area }\end{array}$ & 1 & 2 & 3 & 4 & 5 \\
\hline 6 & $\begin{array}{l}\text { I am willing to write letters in support of } \\
\text { this scenic area }\end{array}$ & 1 & 2 & 3 & 4 & 5 \\
\hline 7 & $\begin{array}{l}\text { I am willing to donate my money to } \\
\text { support environmental protection of this } \\
\text { scenic area }\end{array}$ & 1 & 2 & 3 & 4 & 5 \\
\hline
\end{tabular}

Section 3: Please indicate the extent of your agreement with the following statements about the opinions from important others (e.g. family and friends):

1 =Strongly disagree, 2 = Disagree, $3=$ Neutral, 4 = Agree, $5=$ Strongly agree

\begin{tabular}{|c|c|c|c|c|c|c|}
\hline No. & Item & $\begin{array}{l}\text { Strongly } \\
\text { disagree }\end{array}$ & Disagree & Neutral & Agree & $\begin{array}{c}\text { Strongly } \\
\text { agree }\end{array}$ \\
\hline 1 & $\begin{array}{l}\text { Most people who are important to me } \\
\text { think I should take actions to protect the } \\
\text { environment in this scenic area }\end{array}$ & 1 & 2 & 3 & 4 & 5 \\
\hline 2 & $\begin{array}{l}\text { Most people who are important to me } \\
\text { would want me to protect the } \\
\text { environment in this scenic area }\end{array}$ & 1 & 2 & 3 & 4 & 5 \\
\hline 3 & $\begin{array}{l}\text { People whose opinions I value would } \\
\text { prefer that I engage in environmental } \\
\text { protection in this scenic area }\end{array}$ & 1 & 2 & 3 & 4 & 5 \\
\hline
\end{tabular}

Section 4: Please indicate the extent of your agreement with the following statements:

1 =Strongly disagree, 2 = Disagree, 3 = Neutral, 4 = Agree, 5 = Strongly agree

\begin{tabular}{|l|l|l|l|l|l|c|}
\hline No. & Item. & $\begin{array}{l}\text { Strongly } \\
\text { disagree }\end{array}$ & Disagree & Neutral & \multicolumn{1}{|c|}{$\begin{array}{c}\text { Agree } \\
\text { Strongly } \\
\text { agree }\end{array}$} \\
\hline 1 & $\begin{array}{l}\text { I feel a moral obligation to protect the } \\
\text { environment }\end{array}$ & 1 & 2 & 3 & 4 & 5 \\
\hline 2 & $\begin{array}{l}\text { Due to my own values or principles, I feel } \\
\text { an obligation to behave in an } \\
\text { environmentally friendly way }\end{array}$ & 1 & 2 & 3 & 4 & 5 \\
\hline 3 & $\begin{array}{l}\text { I feel it is important that people in general } \\
\text { protect the environment }\end{array}$ & 1 & 2 & 3 & 4 & 5 \\
\hline
\end{tabular}


Section 5: Please indicate the extent of your agreement with the following statements:

1 =Strongly disagree, 2 = Disagree, 3 = Neutral, 4 = Agree, 5 = Strongly agree

\begin{tabular}{|l|l|l|l|l|l|c|}
\hline No. & Item & $\begin{array}{l}\text { Strongly } \\
\text { disagree }\end{array}$ & Disagree & Neutral & $\begin{array}{c}\text { Agree } \\
\text { Strongly } \\
\text { agree }\end{array}$ \\
\hline 1 & $\begin{array}{l}\text { It is beneficial to me to engage in } \\
\text { environmentally responsible actions }\end{array}$ & 1 & 2 & 3 & 4 & 5 \\
\hline 2 & $\begin{array}{l}\text { It is pleasant to me to engage in } \\
\text { environmentally responsible actions }\end{array}$ & 1 & 2 & 3 & 4 & 5 \\
\hline 3 & $\begin{array}{l}\text { It is wise for me to engage in } \\
\text { environmentally responsible actions }\end{array}$ & 1 & 2 & 3 & 4 & 5 \\
\hline 4 & $\begin{array}{l}\text { It is desirable for me to engage in } \\
\text { environmentally responsible actions }\end{array}$ & 1 & 2 & 3 & 4 & 5 \\
\hline
\end{tabular}

Section 6: Please indicate the extent of your agreement with the following statements:

1 =Strongly disagree, 2 = Disagree, 3 = Neutral, 4 = Agree, 5 = Strongly agree

\begin{tabular}{|l|l|l|l|l|l|l|}
\hline No. & Item & $\begin{array}{l}\text { Strongly } \\
\text { disagree }\end{array}$ & Disagree & Neutral & $\begin{array}{c}\text { Agree } \\
\text { Strongly } \\
\text { agree }\end{array}$ \\
\hline 1 & $\begin{array}{l}\text { Whether or not I take actions to protect the } \\
\text { environment in this scenic area is } \\
\text { completely up to me }\end{array}$ & 1 & 2 & 3 & 4 & 5 \\
\hline 2 & $\begin{array}{l}\text { I have resources, time, and opportunity to } \\
\text { engage in environmental protection in this } \\
\text { scenic area }\end{array}$ & 1 & 2 & 3 & 4 & 5 \\
\hline 3 & $\begin{array}{l}\text { I am confident that, if I want to, I can } \\
\text { protect the environment in this scenic area }\end{array}$ & 1 & 2 & 3 & 4 & 5 \\
\hline 4 & $\begin{array}{l}\text { For me, protecting the environment in this } \\
\text { scenic area is easy }\end{array}$ & 1 & 2 & 3 & 4 & 5 \\
\hline
\end{tabular}

\section{PERSONAL INFORMATION}

Please indicate your social demographic information by ticking $(\sqrt{ })$ ONLY ONE item in each category.

V1. gender: 口 Male 口女 Female

V2. Education: $\square$ Secondary school or below $\square$ high school $\square$ college $\square$ Bachelor $\square$ Master

V3. Age: 口 18 or below 口 19-30 口 31-45 口 46-60 口 61or above

V4. Income: 口 $3000 \mathrm{RMB}$ or below 口 3001-5000 RMB 口 5001-10000 RMB 口 10000RMB or above

V5. How many times have you been to eco-tourism attractions: $\square$ 1-2 $\square$ 3-4 $\square 5$ or above

Thank you for your cooperation. 